\title{
Commentary
}

\section{Postgraduate training in community medicine in India in the era of COVID-19: challenges and remedies}

\author{
Vinu Cherian ${ }^{1}$, Joel Philip ${ }^{2 *}$

\begin{abstract}
${ }^{1}$ Department of Community Medicine, Sree Narayana Institute of Medical Sciences, Chalakka, Kochi, Kerala
\end{abstract} \\ ${ }^{2}$ Department of Psychiatry, The Neurocenter, Vyttila, Kochi, Kerala
}

Received: 08 August 2020

Accepted: 01 October 2020

*Correspondence:

Dr. Joel Philip,

E-mail: joelphilipmd@gmail.com

Copyright: (C) the author(s), publisher and licensee Medip Academy. This is an open-access article distributed under the terms of the Creative Commons Attribution Non-Commercial License, which permits unrestricted non-commercial use, distribution, and reproduction in any medium, provided the original work is properly cited.

\section{INTRODUCTION}

The recent months have witnessed an unprecedented disruption in the processes and methods of training postgraduate students. ${ }^{1}$ The residents who are currently enrolled in post-graduate programs must be equipped with the necessary know-how to become competent specialists in the future. Therefore, the challenges facing these programs in India need to be identified and the necessary remedial measures must be swiftly put in place. In this article, we attempt to identify the most pertinent challenges facing the post-graduate students in community medicine, from their perspective, and also provide individually tailored recommendations to overcome them.

\section{CHALLENGES}

\section{Lectures and seminars}

Enforcing social distancing norms meant that the regular classroom sessions had to be discontinued in favor of web-based seminars. This posed a problem for teaching institutes in peripheral areas with restricted access to broadband internet services. Moreover, these online sessions failed to replicate the spirit of open discussion and the academic back-and-forth that were the highlights of such teaching modules. However, most students and faculty have gradually come to embrace the new format. One recent study noted that students appreciated the ease of attending online sessions and were happy to incorporate such classes in their curricula even after the pandemic came to a close. ${ }^{2}$

\section{Conferences and workshops}

Attending conferences and workshops are invaluable learning experiences for residents. These events offer opportunities to learn from renowned faculty, interact with peers, and present one's research to a diverse audience. Academic presentations are also necessary criteria mandated by the Medical Council of India, which need to be fulfilled, to be awarded the degree of doctor of medicine (M.D) in community medicine. ${ }^{3}$ However, in the current climate, conferences are being replaced by virtual gatherings online. ${ }^{4}$ Although this would appear to be a feasible alternative under these circumstances, it fails to harness the sense of academia and environment of intellectualism that tends to accompany gatherings of some of the finest minds in the profession.

\section{Reduced patient loads}

The proclamation of national lockdowns and overall restrictions on the movement of people has reflected in a drastic drop in caseloads in primary and community health centers and teaching hospitals. ${ }^{5}$ Non-urgent cases and routine in-person follow-ups are being discouraged to limit the spread of the infection. This, in turn, creates fewer opportunities for residents to take pertinent histories, perform clinical examinations, administer vaccines, and observe senior faculty do all of the above. There is no substitute for hands-on training, and these skills will have to be honed by residents in the due course of time. 


\section{Fewer consultants and teaching faculty}

Private medical colleges, teetering under the strain of restricted cash flows from lackluster patient loads, have had to resort to skimming their workforce to survive the pandemic. Senior faculty are often advised to stay home as a precautionary measure to safeguard them from contracting the illness, as they represent a vulnerable population. Senior professors contribute immensely to imparting both theoretical knowledge and practical wisdom to residents, and their inputs are sorely missed in their absence.

\section{Staggered deployment of residents}

The Sree Chitra Tirunal institute for medical sciences and technology, a prominent treatment and research centre in Kerala, had the misfortune of having to shut down a large proportion of their services when one doctor tested positive for COVID-19. ${ }^{6}$ Following this cautionary tale, teaching institutes have taken to deploying only half the available residents to work at a given time, to ensure that the other half would be available to carry on their duties in a similar scenario where mass staff quarantines are called for. This has resulted in additional responsibilities being placed on the limited number of residents, which can be both physically demanding and mentally exhausting.

\section{Dissertations and thesis}

The doctoral dissertation is not only an invaluable learning experience but also a matter of great pride for residents. Today, the COVID-19 pandemic has imposed constraints on the usual protocols of thesis completion. Senior faculty, who are usually the guides for such research, find that they are unable to devote sufficient time to their wards, amid their clinical duties in fighting the pandemic. Regular meetings with residents to evaluate their progress and identify shortcomings also take a backseat during this public emergency. From the perspective of the residents, the reduced caseloads of patients pose difficulties in obtaining the required samples in the stipulated time. To overcome this, residents have to select less challenging dissertation topics, thereby failing to take full advantage of the considerable resources for research that their institute may have to offer. In the long run, the quality of postgraduate research being undertaken may suffer.

\section{Psychological impact of COVID-19}

Working in high-risk environments can have adverse effects on the mental health of post-graduate students. A recent survey revealed that a majority of residents reported high levels of stress when working in the current climate. ${ }^{7}$ This may affect the motivation, morale, and efficiency of residents, which, in turn, may have repercussions on the quality of patient care that is provided. First-hand experiences of contracting COVID-
19, and watching fellow residents fall ill can adversely affect their psychological well-being. ${ }^{8}$ Safeguarding the mental health of residents is one of the foremost challenges faced by course coordinators and teaching faculty today.

\section{RECOMMENDATIONS}

The COVID-19 pandemic has substantially changed the landscape of post-graduate training in community medicine in India. We propose the following recommendations to overcome the challenges mentioned above, corresponding to their order of appearance in the text. There must be a coordinated effort to facilitate a seamless transition to online learning platforms that can host teaching sessions, seminars, etc. Guidelines must be issued to ensure that these modes of 'distant learning' meet agreed-upon standards so that the information sharing is effective and the teaching objectives are met. Post-graduate students must be encouraged to attend virtual conferences and present their research at these forums. Virtual continuing medical education (CME) programs for post-graduates must be organized, ensuring participation from senior faculty of distinguished standing. Academicians must take advantage of the benefits of virtual gatherings, in terms of ease of attendance and minimal travel expenditure, to train and guide the residents in attendance. ${ }^{9}$ Post-graduate students must be trained in the technical, legal, and ethical aspects of telemedicine. ${ }^{10}$ This can enable them to carry forward their skills in history taking and case management to a scenario in which clinical services are provided remotely. The detailed workup of those patients who attend the outpatient departments must be encouraged, to maximize the available learning opportunities. Senior faculty who are mandated to stay at home as a precautionary measure must utilize seminars on online platforms to continue to teach and train post-graduate students. Junior staff must take on the additional mantle of responsibility of overseeing the acquisition of the relevant skills by the residents, through clinical demonstrations as well as personal supervision. Batches of post-graduate students must be divided into smaller groups, with each group under the direct supervision of identified faculty. Efforts must be made, as far as possible, to ensure that the residents do not work more than a stipulated number of hours every week; this can be done by designing suitable rosters to prevent undue physical exhaustion, save time, and increase efficiency. Regular online meetings between the post-graduate students and their dissertation guides must be scheduled, to evaluate their progress and to offer constructive feedback. Faculty may need to identify and redirect specific cases to residents, keeping in mind the reduced patient loads. Case work-ups for the purpose of dissertations may be done through coordinated and scheduled online interactions between patients and residents, wherever possible, to enable them to complete their requisite study samples in the available time. As a last resort, flexibility may be provided to residents who are in the midst of their sample collection and are unable 
to enroll sufficient study subjects under the current circumstances, to submit a systematic review or metaanalysis of their dissertational review of literature as their final thesis. Individual faculty must take up the charges of mentoring small groups of residents and offering open channels of communication to air their concerns. Residents may be directed to form forums to discuss their problems and offer mutual support. Trainees who struggle with symptoms of anxiety, depression, or post-traumatic stress must be encouraged to approach the faculty for honest, non-judgmental discussions about resolving these issues. The Psychiatry department may offer psychopharmacological support if deemed to be necessary. Sufficient personal protective equipment must be made available to residents to safeguard them when carrying out their official duties, and to instill a sense of confidence and security. ${ }^{11}$

\section{CONCLUSION}

The current times are a test of the adaptability, organizational ability, leadership, and resilience of postgraduate students. Trainees in community medicine must be supported to turn the pandemic on its head, utilizing it as a learning experience to face and overcome future trials in their professional careers. COVID-19 has, indeed, thrown up formidable and unprecedented challenges to post-graduate training in community medicine in India. It is of utmost importance that these challenges are promptly recognized and remedied, to ensure that the residents of today are equipped with the necessary skills and expertise, to become the competent public health specialists of tomorrow.

\section{REFERENCES}

1. Richards M, DeBonis K. Psychiatric training during a global pandemic: how COVID-19 has affected clinical care, teaching, and trainee well-being. Psychiatric Services. 2020;1-3.

2. Agarwal S, Kaushik J. Student's perception of online learning during COVID pandemic. Indian J Pediatr. 2020;87:554.
3. Medical Council of India, postgraduate education. Available at: http://www.rguhsqp.com/lic/Postgraduate-Medical-Education-Regulations-2000.pdf. Accessed on 20 June 2020.

4. Persky A, Fuller K, Jarstfer M, Rao K, Rodgers J, Smith M. Maintaining core values in postgraduate programs during the COVID-19 pandemic. American J Pharma Educ. 2020;84(6): 697-702.

5. COVID-19 had material impact on healthcare services business operations. Available at: https://www.newindianexpress.com/business/2020/ju n/09/covid-19-had-material-impact-on-healthcareservices-business-operations-apollo-hospitals2154369.html. Accessed on 20 June 2020.

6. After doctor tests positive, Kerala's SCTIMST heads for shutdown. Available at: https://www.thehindu. com/news/cities/Thiruvananthapuram/after-doctortests-positive-sctimst-heads-for-shutdown/article 31077272.ece. Accessed on 20 June 2020.

7. Nanjundaswamy $M$, Pathak $H$, Chaturvedi S. Perceived stress and anxiety during COVID-19 among psychiatry trainees. Asian J Psychiatr. 2020;54:102282.

8. Philip J, Cherian V. Factors affecting the psychological well-being of health care workers during an epidemic: a thematic review. Indian $\mathbf{J}$ Psychological Med. 2020;42(4):322-3.

9. Ferrel M, Ryan J. The impact of COVID-19 on medical education. Cureus. 2020;12(3):e7492.

10. Dasgupta A, Deb S. Telemedicine: A new horizon in public health in India. Indian $\mathrm{J}$ Community Med. 2008;33(1):3.

11. Herron J, Hay-David A, Gilliam A, Brennan P. Personal protective equipment and Covid 19- a risk to healthcare staff?. British J Oral Maxillofacial Surg. 2020;58(5):500-2.

Cite this article as: Cherian V, Philip J. Postgraduate training in community medicine in India in the era of COVID-19: challenges and remedies. Int J Community Med Public Health 2020;7:4684-6. 